\title{
Pretesting: A Positive Approach to Evaluation
}

\author{
By ANDIE L. KNUTSON, Ph.D.
}

Persons responsible for health education programs have expressed need for some objective means of identifying the strong and the weak points in educational programs while changes are still possible.

Tests can be applied to health education activities while these activities are being planned and carried out. The positive approach outlined here makes use of objective data and methods. It includes two steps: $(a)$ a critical review of the planning process and $(b)$ an objective evaluation of requirements for achieving program goals.

This positive approach to evaluation (1) has been gaining recognition in recent years. It enables the evaluator to contribute to the improvement of a health education program before its structure is fully developed and large funds are expended.

\section{The Planning Process}

One way to assure that each activity be planned in the best possible way is to review systematically and thoroughly each step in planning. Such a review may be focused in terms of several broad questions.

\section{Identification of Needs}

Are the needs which the program is trying to satisfy identified by adequate exploratory fact finding?

A program directed toward improving health practices can have little possibility of success unless it is designed with an understanding of the persons for whom it is intended and for their way of life. One should learn as much as possible about their experiences, interests, motivations, and patterns of behavior insofar as these relate to the problem at hand. What do they need? What do they want? How do they hope and plan to get it? What specific physical, sociological, or psychological characteristics do they have?

Studies of motivation have shown that individuals bring to any situation they face unique patterns of values and needs. As members of groups, individuals have common needs and experiences; they tend to develop common patterns of values. These serve them in sifting out of each new situation certain things to see and hear and to remember and act upon. People accept and use new information if it helps them to achieve their goals. They acquire new attitudes when these fit in with their past experiences and serve a useful purpose. Thus, motivations play a dynamic role in determining what people perceive as well as how they interpret what they perceive (2-4).

Questions such as these might be raised in reviewing a program: How does the problem tie in with those needs and values that most concern the group? In what way does the problem concern them individually? What can they personally do about the problem posed? How will members of this group use the specific in-

Dr. Knutson is chief of the experimental and evaluation services branch of the Division of Public Health Education, Public Health Service. 
formation provided in the educational program?

It is not sufficient for health education to tie in with existing patterns of motivation. To be effective, it must also be attuned to habit patterns, to the way people usually live and behave. What is presented must help them to achieve health goals with a minimum of disruption in their ways of life.

It is unreasonable to expect a ready acceptance of new practices that conflict with deeprooted habit patterns, and it is wasteful to reeducate more than is necessary to achieve adequate improvement in health practices. New attitudes and new practices are most likely to be accepted when they can be easily assimilated.

Complete objective data to answer questions such as these are seldom available to those responsible for developing health education programs. Partial information is sometimes available and local resource persons who have an understanding of the values and habits of the groups concerned may be able to provide additional information while exploratory studies are made to obtain the precise data necessary.

\section{Agreement on Purpose}

Are the program objectives agreed upon, clearly formulated, and written down?

An affirmative answer to this question is fundamental to good planning. Too often programs tend to grow without full agreement on purpose. Members of a planning group may vary considerably in their impressions of agreements that were reached. Staff members may work at cross-purposes for years without knowing they disagree on basic objectives.

In order to be meaningful, health education objectives need to be formulated within the framework of soundly developed and concretely defined program objectives. Health education serves as one of the means of achieving the goals of the total program. One might reasonably question health education activities that do not directly contribute to the broader program objectives.

Confusion and conflict are less likely to occur when objectives are fully discussed and agreed upon, and are then written down in con- crete terms. There should be agreement on the precise action or improvement in health practice one hopes to achieve. Once this desired behavior is precisely defined, one can itemize the specific information and attitudes that need to be acquired in order to perform the new health practice. Such an analysis helps to identify the information that must be highlighted in the program and to omit the information that does not contribute to the attainment of the objectives.

\section{Choosing Right Approach}

Is the method or approach used the one most likely to prove successful in achieving the objectives of the program?

The choice of method used in a health education program is determined by the specific objectives of the program and the way of life of members of the community or audience. An educator who selects his methods without considering the needs, motivations, and patterns of behavior of the people of the community is in reality determining the methods of treatment before making an adequate diagnosis of the problem.

Once specific objectives have been formulated, answers to questions such as the following should be considered before attempting to determine the specific informational content of a program or the methods to be employed: How does the hoped-for improvement in behavior tie in with the pattern of experience and way of life of members of the intended audience or community? How can the action be fitted into the current behavior of the individual with the least physical, social, or psychological conflict? What problems will the individual face in trying to acquire the new practice? What personal adjustments will he have to make if the action is to become an integrated part of his daily behavior?

The final choice of method can be tested by itemizing in parallel columns all objective evidences for and against each method under consideration. Among the things to consider are: evidence of effectiveness in changing behavior, probable cost in time and money in bringing about a given improvement in behavior, and the possibilities of spreading the effect to as many members of the community as 
possible. As health education objectives are defined in terms of actions to be acquired, the process of selecting the educational method to be used becomes more objective and precise. Data available from other studies in human behavior may be drawn upon in making the selection.

\section{Accuracy of Subject Matter}

Is the subject matter to be presented accurate, adequate, and impartial, and will it be accepted by those responsible for supporting and carrying out the program?

While considerable effort is usually made to assure the accuracy and completeness of the content of information or education programs, less attention is given to the equally important problem of assuring that the content will be acceptable to those in a position to support and carry out the program. Yet these individuals hold the key to success or failure.

Funds are sometimes wasted in building, packing, shipping, and setting up exhibits that are then found unacceptable to a conference exhibit committee. Posters and pamphlets have been prepared and distributed and then gone unused because the potential distributor found them unacceptable for use in his place of business. This problem is worthy of early exploration. If suggestions from the potential user or distributor are solicited and considered, costly errors of this kind may be avoided.

Both purposes may be served by drawing such individuals into planning and development. As consultants, they can contribute in many ways. While making their contribution, they will also acquire a personal stake in the success of the program.

When these or other specialists take part in this way, their reactions to content are likely to be most valuable if they are specific. General comments are difficult to interpret and even more difficult to act upon. Vague reactions can be kept to a minimum by asking the specialists to advise on each specific illustration or page under consideration. Insofar as possible, their reactions should be obtained in terms of specific criteria, such as accuracy, adequacy, impartiality, and acceptability. Asking them to indicate the specific error of omission or emphasis whenever they suggest the need for change will encourage positive criticism and eliminate misunderstanding in making revisions.

\section{Objective Measures}

In achieving any health education objective, specific intermediate conditions need to be met. These requirements or conditions may differ somewhat according to the objective to be achieved, but they generally need to be met regardless of what kind of information or educational program is planned.

1. People must be physically exposed to the information or education. They cannot be influenced unless, for example, they can see the exhibit, read the pamphlet, or hear the lecture.

2. Their attention must be attracted and held. To the degree that the information or education fails to interest them, they will not be reached psychologically even though they are physically present.

3. They must find in the information something that will satisfy their wants or help them in achieving their goals. Unless it ties in with their motivations, they have no real basis for action.

4. The action recommended should be in accord with the way people usually behave. Otherwise, action may lead to conflict in personality or adjustment, or to conflict in social behavior.

5. Words, concepts, and illustrations need to be understood. If they are not understood, people may remain uninformed or may become misinformed and confused.

6. They must really understand the point of the message. It is necessary that the primary purpose be correctly interpreted because the success or failure of the entire program may hinge upon this common agreement as to purpose.

7. They must acquire and retain the information and attitudes essential for action.

The foregoing intermediate requirements may be referred to briefly as "conditions necessary for effectiveness" to distinguish them clearly from "evidence of effectiveness," that is, evidence that behavior changes have been achieved.

Conditions necessary for effectiveness may be 
likened to a series of screens through which members of the potential audience must "filter" in order to be influenced by a program $(5,6)$. Trying out the screens with a sample of members of the audience gives a rough idea of how well the program may be expected to work when used with the total audience.

Part or all of a group may be lost through failure to satisfy any one of these conditions: For some reason, the medium or program material used may not be presented to them; if presented, it may fail to attract attention and sustain interest; if interesting, it may be too difficult for them to comprehend. As members of the audience are "screened out" through failure of the program at these specific points, the number who can be influenced is very much decreased. Once a member is lost, there is no way to win him back until the condition which led to his loss is satisfied.

If any of these conditions are not satisfied, those persons for whom the condition is not satisfied are lost to the program:

Exposure - How many persons will be reached physically?

Attention and Interest-How many persons physically reached will be reached psychologically?

Motivation-For how many reached will the program offer a means of satisfying a want or achieving a purpose?

Pattern of Behavior-For how many will the action that satisfies a want in this manner be in accord with the way people usually behave?

Comprehension-How many will understand the words, concepts, and illustrations used?

Understanding of Purpose-How many will really understand the point of the message?

Learning and Retention-How many will acquire and retain the information and attitudes essential for action?

Caution is necessary to assure that satisfaction of these conditions is not interpreted as evidence of effectiveness. Evidence that the specific goals of a program have been achieved is the only valid criterion of success (1).

Pretests of movies, slide films, exhibits, posters, pamphlets, and other media may be used to determine whether or not the conditions necessary for effectiveness are being satisfied. Such pretests may be made while scripts and story boards are still in rough form-before plans for production are completed. On the basis of evidence obtained at this early stage, fundamental changes may be indicated. Necessary improvements can then be made quickly at a minimum cost to the program.

The pretest should determine whether each specific condition is satisfied for the members of the audience or population. It should also identify reasons for failure if the condition is not met for some members of the audience. Reasons for failure, when identified, will usually suggest means of improvement. Barriers to success may then be removed before the program is put into operation.

Any pretesting or pre-evaluation should be made on members of groups similar to those for whom the educational program is intended. Persons of different economic, social, and educational levels vary so widely in their experiences and in their goals in life that they cannot view social situations in the same manner. Professional persons reading a pamphlet developed for a group with limited education may react in a manner completely different from the nonprofessional worker for whom it is planned. Only by testing the pamphlet on a sample of lay persons for whom it is intended can we gain some assurance that it can communicate the message it carries.

The approach outlined here is not intended as a "blueprint" for meeting all problems of pretesting or evaluation. The needs of public health vary endlessly, both in kind and extent; educational programs developed to meet these needs vary accordingly. Major changes or variations may be required in the pretest approach and the techniques employed depending upon the particular program being evaluated. A wide range of variations exists both in the broad pretest pattern and in the techniques adapted or developed to test achievement of specific program steps.

\section{Summary}

Through a critical review of the planning process and through objective pretesting, an evaluator can contribute to the improvement 
of health education programs as they are being developed and before large funds are expended.

The critical review should be made before pretesting is attempted for there is little value in pretesting a program that has not been adequately planned. Such a review should consider: (a) Are the needs which the program is trying to satisfy identified by adequate exploratory fact-finding? (b) Are the program objectives agreed upon, clearly formulated, and written down? (c) Is the method or approach used the one most likely to prove successful in achieving the program objectives? (d) Is the subject matter to be presented accurate, adequate, and impartial, and will it be accepted by those responsible for supporting and conducting the program?

The pretest should be planned in terms of certain specific conditions that need to be satisfied in order to achieve program goals. With these conditions met, the program will have a much better possibility of being successful in achieving changes in behavior. Pretests determine whether or not the conditions are being satisfied and yield data useful for improving a program. Although pretesting will not guarantee the success of a program, it will greatly increase the chances of success.

Many aspects of the problem of motivating people to improve their health habits are still unknown. Exploratory research in this area is badly needed. We also need to encourage and diligently pursue post-evaluation and controlled studies of programs, both to determine program effectiveness and to identify unknown aspects of success or failure. Meanwhile, through pretesting, we can apply information now available.

\section{ACKNOWLEDGMENT}

This statement of concept was made possible by the following Institutes and Divisions of the Public Health Service which have provided the necessary financial support and practical problems for investigation: The National Cancer Institute, the National Heart Institute, the Division of Chronic Disease and Tuberculosis, and the Division of Venereal Disease. Helpful advice and assistance have been received from Dr. Mayhew Derryberry and members of the staff of the Division of Public Health Education, especially Dr. Benjamin Shimberg.

\section{REFERENCES}

(1) Knutson, Andie L.: Evaluating health education. Pub. Health Rep. 67: 73-77 (1952).

(2) Cantril, Hadley: The "why" of man's experience. New York, the Macmillan Company, 1950.

(\$) Hastorf, A. H., and Knutson, A. L.: Motivation, perception, and attitude change. Psychol. Rev. 56: 88-89 (1949).

(4) Murphy, Gardner : Personality. New York, Harper and Brothers, 1947.

(5) American Child Health Association: Physical defects; The pathway to correction. New York, N. Y., 1934.

(6) Gallup, George: The quintamensional plan of question design. Pub. Opinion Quart. 11: 385-393 (1947).

\section{Dr. Hunt Appointed Assistant Surgeon General}

Dr. G. Halsey Hunt has been appointed an Assistant Surgeon General of the Public Health Service. He will serve as an associate chief of the Bureau of Medical Services, which is under the direction of Dr. Jack Masur.

Entering the Public Health Service as a commissioned officer in 1936 , Dr. Hunt served on the surgical staffs of several of its hospitals, and in 1947 he joined the Bureau of Medical Services as assistant chief of the Division of Hospitals. He became chief of the division in 1949.

Dr. Hunt received his medical degree from Columbia University College of Physicians and Surgeons in 1928. He is a fellow of the American College of Surgeons and in 1951 was elected to the Board of Governors. He is also a member of the Surgery Study Section, National Institutes of Health, Public Health Service. 